\title{
ATCKs as expatriates: Turnover intention and adjustment examined
}

Hello! Thanks for taking an interest in our research on Adult Third-Culture Kids (ATCKs). We think this work is super interesting because it provides evidence to contradict the common claim that adults who are expatriated in childhood are more likely to be retained in traditional expatriate work. Everything about this work, including the data and analysis code, is available on the OSF: osf.io/e8yp2/ but please note this work has not been through peerreview and is currently a preprint. We haven't yet found a final home for this work, so we welcome all feedback! If you have any suggestions for how to improve the manuscript, or indeed where might be a suitable home, don't hesitate to get in touch!

Grania Mackey \& Thomas Rhys Evans 


\begin{abstract}
Purpose

Adult third-culture kids (ATCKs), or adults who were living abroad in expatriated families during childhood, have been theorised to possess resources to meet the increased stressors and demands of overseas assignments due to their higher cross-cultural competency, adjustment, and security in risk-taking. This research sought to compare the turnover intention of ATCKs with that of adults with mono-cultural backgrounds, in expatriate roles, and to see whether this experience provides incremental predictive validity for turnover intention over and above demographic and adjustment factors.
\end{abstract}

Design

This research used a quantitative, cross-sectional design implemented through an online questionnaire $(n=206)$.

Findings

Results reported that ATCKs showed significantly higher levels of turnover intention than those with mono-cultural backgrounds. Furthermore, this background predicted an additional $3.3 \%$ of variance in turnover intentions above that of various adjustment indices.

\title{
Originality
}

This research provides initial evidence to dispute the claim that adults who are expatriated in childhood are more likely to be retained in traditional expatriate work and suggests future research to investigate leveraging ATCK skills in alternative expatriate contexts.

\section{Practical implications}

These results may allow international organisations to better understand the potential benefits of ATCK employment as expatriates and their role in a global environment in need of increased retention and mobility.

Keywords: TCK; ATCK; expatriate turnover; expatriate retention; turnover intentions; cross cultural management; international management 


\section{Introduction}

Expatriate studies have become increasingly relevant in a global employment market defined by mobility and international perspectives. $72 \%$ of global company executives see an increasing need for robust global mobility programs which prioritise strategic long-term talent management and retention (EY 2014). Expatriates are costly for multinationals and with expatriate assignment failure comes high financial and psychological costs for the assignee and their family, as well as potential reputational damage to the company involved (Guttormsen et al. 2018). Whilst premature return rates commonly framed between 16-40\% (Lazarova and Caligiuri 2001) likely over-exaggerate the prevalence (Harzing 1995), there are a number of ongoing complexities associated with the recruitment and retention of expatriates. Harzing cites factors like changing work ethos and the increasing numbers of dual career couples, as responsible for reducing the pool of global candidates. With a decreased general pool of candidates from which to recruit, it is ever more vital that selection procedures are targeting those who are most likely to succeed on an overseas assignment.

Of the estimated 66.2 million expatriates worldwide (Finaccord 2018), over $80 \%$ are bringing their families with them (Brookfield Global Relocation Services 2016; Schütter and Boerner 2012), with spousal and family adjustment cited as a deciding factor in retention (Lazarova et al., 2001). The number of children from these mobile families ("third-culture kids" or "TCKs") is increasing in line with increased mobility, and it has been speculated that employees with this early international experience ("adult third-culture kids" or ATCKs) may be more culturally adaptable and therefore better suited to foreign assignments than those with monoculture backgrounds (Selmer and Lam 2003; Selmer and Lauring 2014). International organisations look to benefit from research into this area as expatriate assignment failure is costly (Kumarika Perera et al. 2016) and targeting candidates who are more likely than others to stay on assignment provides an opportunity to reduce costs as well as optimise long-term talent planning (Bonebright 2010).

\section{Turnover Intention}

The emergence of many personal factors relating to expatriate assignment success or failure has led to researchers looking more closely at what such categories mean, beyond the traditional definition of expatriate failure as premature departure. Harzing and Christensen (2004) argue that a premature departure must be contextualised in order to be understood and is not always a mark of "failure", for example in the case of restructuring or the employee leaving to take up a better offer. They conclude that the concept of expatriate failure is an "empty term" without such contextualisation, and that expatriate assignment performance would be more fruitfully explored via established performance management and turnover research, including examining competencies and antecedents to turnover.

Turnover is defined as employees' voluntary severance of employment ties and is determined by a wide range of factors (Hom et al., 2012; Maertz and Camption, 1998), including that of both professional and personal context (Hom et al., 2017). Hom et al. (2012) note that turnover increases costs, is disruptive to organisational operations, increases health and safety issues, and affects the quality of customer service, in addition to the long-term impacts of losing professional talent. This last factor in particular is a key issue in expatriate retention problems (Collings et al. 2007).

Turnover intention in ATCKs has not been specifically examined in the literature to date, however it is possible to deduce from the extent of early departures in expatriate turnover that 
there are possible connections with the attributes of ATCKs. Abe (2018) investigated ATCKs' developmental paths and concluded that ATCKs develop towards greater maturity and adjustment during adulthood than others, with higher resilience and more adaptive cognitive and affective styles. In corroboration, ATCKs are also found to demonstrate a preference for an international component to their lives (Cottrell 2002; Cottrell and Useem 1996). This preference for international mobility contributes to the proposition by Selmer and Lam (2014) that ATCKs are both well prepared and suited to expatriate careers. Bonebright (2010) noted their ability to handle change as a key attribute, whilst Westropp et al. (2016) cite the variety of international experience, multilingualism, ethnic diversity and openness to experience found in ATCKs as relevant factors for expatriate role fulfilment. This finds some support from Stokke (2013), who studied the global mindset of ATCKs to find emergent themes of their abilities as changers, communicators, creative problem solvers, and global citizens. She concluded ATCKs had the potential to be the global leaders in a worldwide work environment that is increasingly non-linear in terms of career progression.

In order to investigate the speculative suggestion that ATCKs are more likely than non-ATCKs to be more adjusted and therefore more suited to expatriate roles, this research therefore first investigates turnover intention in both ATCKs and non-ATCK expatriates.

H1 ATCKs in expatriate roles have lower turnover intentions than non-ATCKs in expatriate roles.

\section{Adjustment and Integration}

One of the key determinants of turnover in the expatriate literature is adjustment (Black et al. 1991). Greater adjustment to the terms of ones' placement typically leads to greater likelihoods of assignment completion. Identifying the factors inherent in assignment success has driven a substantial body of research, which has found that expatriate adjustment to life in the host country is one of the critical elements (Sterle et al. 2018), with failure to adjust the leading factor in early assignment withdrawal (Caligiuri 1997). Reasons for adjustment retention or turnover are proving harder to identify, though there are various factors which may play a part. For example, expatriates experience lower well-being and greater mental ill-health compared to non-expatriates (Font et al. 2012; Aalto et al. 2014), which may affect adjustment and prompt early return from assignment (Wang and Takeuchi 2007; Al-Maskari et al. 2011). Following this focus on mental health, Doki et al. (2018) identified six component factors of expatriate stress: communication, cultural differences in the workplace, daily life, relationships with family and colleagues, financial problems and social inequality. These factors suggest that personal abilities, in addition to professional abilities, matter when it comes to adjusting to expatriate life. Additionally, as Horak and Yang (2016) note, local social factors can differ by country and sometimes region in terms of their nature and characteristics. The ability of expatriates to negotiate the local environment and to be adaptable and flexible is therefore regarded as crucial for staying on assignment (Gordon and Teagarden 1995:18).

Black et al. (1991) integrated the adjustment literature to identify three dimensions of expatriate adjustment: work adjustment is the degree of psychological comfort with the expatriate role; general adjustment refers to the local culture and living standards; interaction adjustment is regarding the expatriate's ability to integrate with the local community. Black et al. (1991) developed a scale to measure the three dimensions of their findings, which has been widely used in the literature to support research into predictive factors of such adjustment. Results of this research have shown factors such as work experience abroad, personality, and preparation, to be related to adjustment in expatriates (Black and Mendenhall 1990; Caligiuri 
et al. 1999; Shaffer et al. 1999). Shaffer et al. (1999) tested the Black et al. (1991) model in some depth and provided promising support for the multi-dimensionality of expatriate adjustment. To date, research has primarily focused on specific nationalities and locations however. For example, Selmer (2002) found that although some previous international work experience helped newly arrived expatriates in Hong Kong to adjust to their work, it appeared to have no effect regarding general and interaction adjustments. The extent to which such highly localised conclusions generalise to the wider expatriate population is unclear to-date.

There are a number of adjustment-related factors which show promise for the prediction of assignment completion. For example, expatriate community involvement has been associated with stronger retention cognitions (Yunlu et al. 2018), and Lee et al. (2018) found that previous student travel experience and cultural intelligence were positively linked to expatriation willingness. These studies are representative of a redirection of the literature towards identifying individual experiential factors and their contribution to expatriate retention and adjustment (Lazarova and Cerdin 2007). Guttormsen (2018) reflects this point of view by arguing that focusing research on the lived experience and experiential factors underlying expatriation at a personal level, at a regional level, and across multiple working sectors, will drive the greatest developments in expatriate literature

Given that speculation regarding the suitability of ATCKs as expatriates is relatively recent, there is little consistent specific research into their adjustment abilities at work or as expatriates. Selmer and Lauring (2014) compare ATCKs to adult mono-culture children, specifically looking at general adjustment and work adjustment in self-initiated expatriates. As expected, ATCKs have significantly higher general adjustment, though not work adjustment. The authors note that expatriate adjustment is influenced by various aspects of the host country that the expatriate has experienced, as found by Caligiuri and Tarique (2012). Zhu et al. (2016) examined expatriate work adjustment in traditional expatriates and provided further evidence for significant between-individual variation in work adjustment over time, with higher initial work adjustment in those with previous international experience. The same study also found that personal resources, such as high core self-evaluation, were related to higher initial adjustment on assignment abroad, and suggest that further assessment of prior experience with dynamic resources would provide further insight. More profoundly entrenched effects, therefore, such as those developed in childhood by TCKs' self-identification as belonging to all of the cultures that have touched their lives (Lyttle et al. 2011), may be central to an enhanced development of this kind (Selmer and Lauring 2014). In related research fields, this has been called "cultural intelligence": the ability to gain or adjust behaviours in a new cultural environment (Ang et al. 2006) and has been postulated to positively correlate with expatriate adjustment (Lee and Sudoko 2010).

A recent paper (Lauring et al. 2019) has explored the relationship between interaction adjustment and personal development in expatriates and whether it differs for ATCKs and nonATCKs. The results show improved experience of personal development in both groups, with a stronger effect for ATCKs when interaction adjustment increases. As many expatriates are motivated to take roles abroad to build their personal development (Lauring et al. 2014), this suggests that ATCKs may have more motivation to remain expatriated. This line of enquiry is a promising extension of a body of research which confirms that interactions between expatriate workers and host-country nationals have positive effects for not only expatriate adjustment, but also expatriate performance (van Bakel 2018).

There are scant studies that further analyse or identify the nature of local integration for expatriates, despite such promising results. There are many global locations with a high 
percentage of expatriate or non-local populations which may provide an alternative avenue for non-ATCKs in terms of in-country adjustment. For example, Basel in Switzerland has a current expatriate population of $36 \%$ and consistently rates highly as a long-term expatriate location (Business Insider 2019). This could have implications for expatriate adjustment research in expatriate locations with differing expatriate populations.

The current study is therefore also interested in the extent to which ATCK status may provide additional understanding of turnover above and beyond the adjustment factors noted above, which may be indicative of personal experiences or resources which facilitate assignment completion.

$\mathrm{H} 2$ ATCK status can explain significant variance in turnover intention (as determined by $\mathrm{p}<.05)$ in a model including age, years in country, general adjustment, expatriate community adjustment and local adjustment.

\section{Method}

\section{Design}

This research used a quantitative cross-sectional questionnaire. First, the current study considered the difference in turnover intentions between ATCK and non-ATCK in expatriate roles. Second, the predictive value of ATCK status for turnover intentions was examined after controlling for demographics and adjustment variables.

\section{Target Sample}

The target sample consisted of working expatriates over the age of 25 with either TCK or monocultural childhoods. This was to include those who have largely completed studies or training and are in a professional career role. Age is known to correlate with career commitment (Colarelli and Bishop 1990) and young participants may be a confounding factor for specific role commitment if still in emerging adulthood, therefore a minimum age of 25 was chosen based on accepted theory regarding the end of this period (Arnett 2000). The definition of a TCK is any individual domiciled, for two or more years between the ages of 5 and 16 years, in a country other than their primary passport country (Pollock and Van Reken, 2009) and this inclusion criteria for ATCKs was used.

Target participants were additionally asked to specify how long they have been in their host country to ensure they had passed the adjustment period common in expatriate assignments. This period is described as a U-curve, with the lowest or most demotivated point falling at between six months and three years (Hippler et al. 2015), therefore a three-year minimum was required.

\section{Power Analysis}

A priori testing using GPower 3.1.9.4 (Faul et al. 2009) calculated that a sample size of 88 participants per group would be required to detect an effect size of $\mathrm{d}=0.5$, a moderate effect, in a one-tailed between-groups t-test with $\alpha=0.05$ and high power (.95).

\section{Participants}

Participants were recruited through online expatriate Facebook and LinkedIn groups and ATCK groups with active moderators whose gatekeeper permission was sought prior to posting. Criteria information was provided on the group page as well as an overview of the 
research and a link to the questionnaire where participants were required to read and fill a consent form. A participant information sheet was also available at this stage, as well as a debrief sheet following completion of the questionnaire. There were 206 participants in total, $133(65 \%)$ of whom were ATCKs, $72(35 \%)$ were raised in a single country (non-ATCKs).

Fifty-three males $(26 \%)$ and $153(74 \%)$ females took part, mostly aged between $25-34(\mathrm{n}=51$, $25 \%), 35-44(\mathrm{n}=63,31 \%)$ or $45-54(\mathrm{n}=65,32 \%)$ with 22 participants aged between 55 and 64, and 5 aged between 65 and 74. The majority of respondents originated from the United States $(\mathrm{n}=49,24 \%)$ and the United Kingdom $(\mathrm{n}=46,22 \%)$. The largest proportion $(\mathrm{n}=59$, $29 \%$ ) were hosted in Switzerland, followed by the United States ( $\mathrm{n}=44,21 \%)$, United Kingdom $(n=11,5 \%)$ and France $(n=10,5 \%)$.

\section{Measures}

To measure general adjustment, local adjustment, expatriate group adjustment, and turnover intention, four self-report questionnaires were required. All materials adopted can be found in the data codebook on the OSF page: osf.io/ e8yp2/

General adjustment was measured using Black's (1988) seven item model of general expatriate adjustment, with an Omega reliability $\omega=0.88$. Local adjustment was measured using Black's (1988) three item model of expatriate interaction, with an Omega reliability of $\omega=0.94$. Expatriate group adjustment was measured using a modified version of the expatriate interaction questionnaire which is adjusted to refer to expatriate social groups and is called the model of expatriate adjustment with an Omega reliability $\omega=0.92$. Responses to all of these measures are assessed using a five-point Likert scale ranging from strongly agree to strongly disagree.

Traditionally, turnover intention has been defined and measured at the individual level by asking employees whether they intend to leave their organisation within a certain timeframe (Meyer and Allen 1991). This is regarded as a good predictor of actual turnover (Kivimäki et al. 2007). To evaluate turnover intention, Meyer and Allen's (1991) three-component model of organisational commitment and turnover intention (Appendix 4) was used. Respondents were asked how often they think about quitting their organization, how likely it was that they would search for a position with another employer, and how likely it was that they would leave the organization in the next year, on a five-point Likert scale ranging from strongly agree to strongly disagree. The Omega reliability $\omega=.89$.

\section{Procedures}

Approval for this study was obtained from the Coventry University Psychology Ethics Committee in accordance with the British Psychological Society (BPS) Code of Ethics and Conduct (BPS 2018), the BPS Code of Human Research Ethics (2014), and the BPS Ethics Guidelines for Internet-mediated Research (BPS 2017). All data has been stored according to General Data Protection Regulation (GDPR) (2016) requirements. Participation occurred online. Participants were provided with an information sheet prior to the questionnaire and following completion, a debrief sheet.

\section{Results}

H1: Turnover Intention in ATCKs and non-ATCKs 
Data screening indicated that the data did not contain outliers, and Levene's test of homogeneity of variance was met $(p=0.61)$. However, the data did not meet the parametric assumption of normal distribution, with negative kurtosis observed in both groups. This was confirmed by a Shapiro-Wilk test of normality ( $p<0.01$ for the ATCK group and $p<0.01$ for the non-ATCK group). The data was therefore analysed using the non-parametric MannWhitney U test.

The mean turnover intention score across both groups was $2.94(\mathrm{SD}=1.21)$. Women had a higher mean score of $2.97(\mathrm{SD}=1.28)$ than men, who had a mean score of $2.85(\mathrm{SD}=1.16)$. The mean score of the ATCK group was 3.11 ( $\mathrm{SD}=1.21)$ and the mean score of the nonATCK group was $2.64(\mathrm{SD}=1.16)$. The means and ranges of the ATCK and non-ATCK groups are visualised in a raincloud plot (see Allen et al., 2019) in Figure 1. There was a small yet significant difference in the turnover intention scores between the ATCK group and the nonATCK group $(W=5920, p=0.005, r=-.20$, Cliff's Delta $=.22)$, with the ATCK group revealing a higher turnover intention than the non-ATCK group. H1 was therefore not supported.

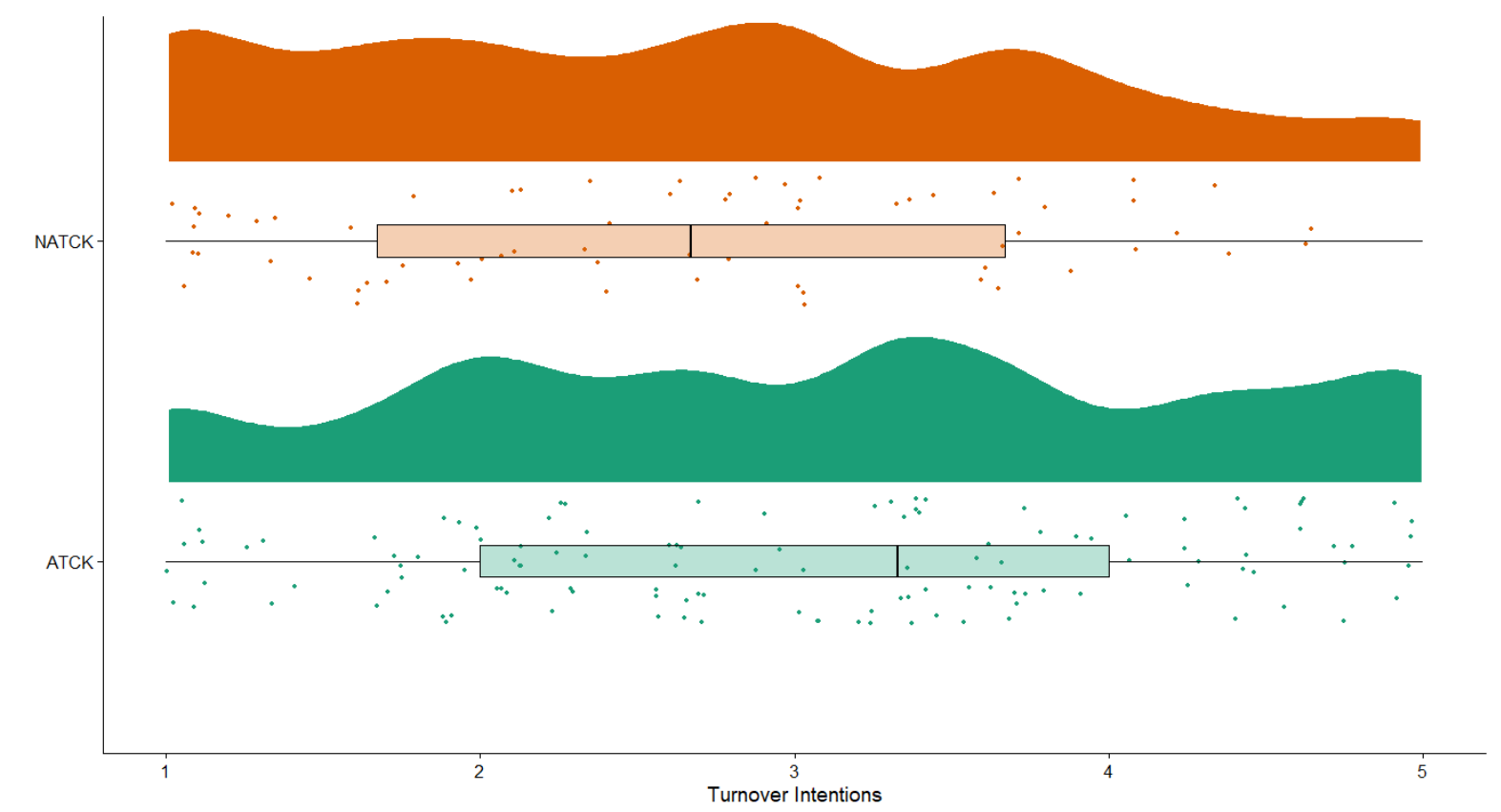

Figure 1: Raincloud Plot of turnover intention in sample groups. (NATCK $=$ non-ATCK)

\section{H2: ATCK predicting Turnover Intentions}

Following data screening, assumptions for a multiple regression stepwise analysis were met and the analyses proceeded as anticipated. A Pearson correlation matrix of the combined ATCK and non-ATCK sample can be found in Table 1.

\section{[Insert Table I here]}

A stepwise regression was conducted to explore the incremental predictive value of ATCK status for turnover intention. In step 1, age, sex and years spent in current country predicted an insignificant portion of variance $\left(R^{2}=.001,95 \% \mathrm{CI}[.00, .06]\right)$. In step 2, general adjustment, 
host interaction and expatriate interaction were added. General adjustment (beta $=-.20$ ) and host interaction (beta $=-.10$ ) were significant predictors, and together they all contributed to an additional $6 \%$ of variance $\left(R^{2}=.082,95 \%\right.$ CI[.01,.14]). In step 3, TCK status was added. This was a significant predictor of turnover intentions (beta $=-.18$ ) and contributed to an additional $3.3 \%$ of variance $\left(R^{2}=.115,95 \%\right.$ CI[.02,.17]). Full regression findings are presented in Table 2.

\section{[Insert Table II here]}

\section{Discussion}

Contrary to predictions (H1), the results demonstrated that ATCKs have higher turnover intention in expatriate roles compared to those with mono-cultural backgrounds. A possibility may be that ATCKs regard themselves as "global nomads", who prefer the potential mobility of international living rather than the consistency of one international location (Cottrell 2002; Cottrell and Useem 1996), something lacking substantive empirical examination in the literature to date. Barringer (2000) explored the counselling needs of TCKs and identified change as something on which TCKs commonly rely. This may sometimes manifest as an inability to make a commitment in personal relationships (Walters 2006), despite a paradoxical ability to forge deep friendships quickly (Schaetti \& Ramsey 1999). How this may translate to career or job commitment has yet to be examined in the literature, though, in a study of 258 ATCKs' degree and career choices, it has been suggested that this underlying desire for high mobility is a key element to the career choices of ATCKs (Byttner 2012). It is therefore likely that higher mobility expatriate roles may be most suitable for ATCKs, with their ability as "global ambassadors" put to profitable use by multi-national companies (Byttner 2012).

In corroboration, in previous research, ATCKs show higher levels of flexibility, selfdetermination and independence (Selmer and Lam 2014), which may suggest that this group are adept at negotiating change and are unafraid to explore further career options and therefore are prepared to leave their role if it does not meet their expectations. In effect, the role itself, rather than the specific country, may be the greater priority. There is tentative support for such a possibility in their study choices (Ender 2000), which reveal mostly vocational directions such as medicine, teaching and law. The implication here is that employers may need to look beyond the traditional financial incentives and short-term career development offers in expatriate packages if they are to attract and retain high calibre, adaptive expatriate employees. In short, offering tangibly and personally meaningful roles, long established in work design theory (Grant et al. 2011) may be key to retaining this population.

The moderate relationship between turnover intentions and adjustment corroborates previous research revealing that ATCKs tend to adjust more readily to local communities when living abroad (Caligiuri and Tarique 2012; Selmer and Lauring 2014). Although most expatriate roles tend to be in developed, international urban centres (EY 2014), there is evidence that developing countries and developed countries trying to establish certain industries and expertise, such as Mexico, struggle to attract relevant talent willing to navigate the crosscultural challenges (Wade 2016). De Eccher and Duarte (2016) have established that how a country is perceived by prospective expatriate candidates depends on individuals' background and social identities, and that the less well known and less developed countries attract fewer accepted offers. ATCKs may then provide the answer for international companies hoping to 
build centres of excellence in locations with less familiar, and therefore less attractive, characteristics for non-ATCK expatriates.

That this research did not find a significant predictive value or relationship between expatriate community adjustment and turnover intention may reflect expatriate populations. Research shows that expatriate communities find expatriate groups a stabilising influence, a "social survival strategy" when integration is key to expatriate role success (Beaverstock 2011). Beaverstock's (2011) research centred on expatriates in Singapore, where such clubs are commonplace for the numerous expatriates. Switzerland's expatriates comprise around $30 \%$ of the population (Business Insider 2019). However, expatriates in Switzerland accounted for $29 \%$ of the respondents to this research and did not reveal a significant preference for this community, nor was it suggested that it influenced their turnover intention. This, alongside the fact that Business Insider (2019) also cites Switzerland as a favoured expatriate location, raises thought-provoking questions about the nature of social integration and expatriate role outcomes. However, the respondents to this research also revealed a strong general adjustment, whether ATCK or not, which suggests that Switzerland and the United States $(21 \%$ of respondents' current country in this study) have common ground in managing to retain their expatriates. The target sample was screened for having passed the 3-year U-turn adjustment period, which may not reflect all expatriate populations. However, both countries have established immigration programmes and may thus provide more effective means of general and local integration; for example, Switzerland's "cultural distance" policy for migrants and its contribution to migrants' language-learning may aid in this respect (Yeung 2016).

This research corroborates previous findings that expatriates in general are more likely to remain in their roles if they experience general adjustment to expatriation. For example, Black et al.'s (1991) integrated expatriate adjustment model identifies adjustment to local living standards and culture as key components in expatriate retention. However, it is repeatedly emphasised in the literature that adjustment is a multi-faceted and multi-moderated phenomenon that cannot rely on generalised categories (Schaffer et al. 1999; Aycan 1997; Puck et al. 2016) and must look at the detail of the different groups of expatriates and their differing approaches and needs (Selmer 2006), including personal experiential factors, and the role each factor plays in the overall picture (Lazarova and Cerdin 2007). Our regression analyses suggested that ATCK status predicted an additional 3.3\% of variance in turnover intentions above and beyond that of general adjustment. Given the weight afforded to general adjustment in the literature, this modest additional variance suggests that there may be substance to the experiential hypothesis $(\mathrm{H} 2)$, worth investigating further.

In this respect also, it is pertinent to note that the ATCK group in this study reported lower general adjustment than those with mono-cultural backgrounds, which has not been previously observed in the literature. Selmer and Lauring (2014) found the opposite results; however, their research focused on a homogenous sample of academics in Hong Kong and so may not be comparable. As general adjustment refers to local culture and living standards, it is a surprising outcome of this research for the ATCK group who otherwise show stronger local adjustment, and emphasises the importance of future research into the antecedents of general adjustment in differentiated groups of expatriates and how this may impact turnover.

This study's results were derived from predominantly female respondents and confirms that women in general across both groups reveal high local adjustment, regardless of ATCK status. Previous research indicates that women adapt more readily than men to expatriation in Asia (Selmer and Leung 2003), Switzerland (Salamin and Davoine 2015) and Spain (Haslberger 2010). Female expatriates have historically been marginalised as "trailing spouses" (van 
Bochove and Engbersen 2013) but are increasingly working abroad in their own careers and are rated more highly than men in expatriate work performance (Foldes et al. 2017). This result, therefore, holds additional benefits for international companies hoping to find new avenues of recruitment; it has previously been suggested that the large numbers of existing single-career couples where the male is the working spouse, could be developed into willing dual-career couples by companies looking at consolidating expatriate retention (Känsälä et al. 2014).

\section{Limitations and Future Research}

The findings of this study should be interpreted in the context of its potential limitations. For example, the sample was geographically diverse and this was not controlled for in the analyses due to many areas with low levels of representation and therefore heightened likelihoods of type 1 errors. Cultural differences between the participants' countries of origin and their host countries (Doki et al. 2018), as well as between the participants' home country work culture and that of their present workplace (Shin et al. 2006), may have contributed to the outcomes of the analysis. Future research in this area may benefit therefore from conducting secondary analyses of such data or controlling for cultural values and distance.

Other possible limitations of this research lie in its use of a cross-sectional self-report design. Whilst there was no evidence of common method bias identified, future research is encouraged to capture actual turnover rates wherever possible, and to use objective or behaviour-based measures to counteract self-report bias (Ortner and Vijver, 2017). Furthermore, cross-sectional data inhibits causative conclusions (Sousa-Poza and Henneberger 2004). Future research should ideally conduct longitudinal analyses to enable causality and inter-variable reciprocity claims to be made (Albrecht and Andreetta 2011).

An area not investigated by this study concerns language. There is some evidence that language fluency has significant interactions with the influence of role conflict on expatriate adjustment (Schaffer et al. 1999) and it has been suggested that language fluency should be added to Black et al.'s (1991) model of adjustment. There is no evidence that it directly affects general or local expatriate adjustment however, although research has not accounted for the disparate home languages encountered in any one expatriate employment location, perhaps due to a focus on native English speakers in the literature (Shin et al. 2006).

Certain aspects of employment were also not explored, e.g. the type of work, the level of responsibility or stress, workplace relationships, and the reasons for wishing to leave. Given generally high levels of expatriate stress (Harvey and Buckley 1997), further research may consider attending to these factors when examining expatriate and ATCK turnover intention. The inherent implications for retaining expatriates should thus be explored using an expanded criterion, perhaps within the job demands-resources model (Demerouti et al. 2001), to identify specific expatriate demands relating to turnover intention and perceived buffers.

\section{Conclusion and Implications}

This research aimed to examine whether childhood expatriation affected turnover intention in current expatriates. It further explored the potential influence ATCK status held upon turnover intention, over general, local and expatriate community adjustment. Results revealed a significant difference between the two groups, with ATCKs displaying a higher turnover intention than expatriates with a mono-cultural background. Furthermore, this background demonstrated incremental validity for predicting turnover intentions over and above that of adjustment.

These findings present a more nuanced relationship between ATCKs and adjustment than uncovered heretofore, which should be acknowledged within future investigations. The results 
suggest that there is a complex picture to be uncovered, which may be served by more detailed screening of, for example, the length of time abroad in childhood, the age at which that time was spent, whether it was a temporary assignment or self-initiated and open-ended role, the type of global role chosen in adulthood (short-term vs long-term, travel vs assignment, local interaction vs intra-organisational), and in turn the effects on adjustment and assignment success. These factors may generate further insight into ATCK choices and potential as global and cross-cultural workers.

Having established a significant difference between the ATCK and non-ATCK populations, there remain numerous avenues to pursue in terms of how ATCKs perceive their experience in expatriate roles and how their substantial abilities may be best served by global demands in the workplace. Much remains unknown regarding ATCKs, but this research goes some way towards expanding our knowledge of personal experience and its relationship with international assignments and expatriate work life by exposing one significant inter-group difference. Expatriation carries substantial burdens, many of which remain potentially addressed by the specific abilities of ATCKs. This is an area which still demands interest for global employers, though there are many ambiguities outstanding regarding their suitability, which could be addressed in future research centred on specific abilities, job demands and their intention to stay in their current expatriate role. 


\section{Conflict of Interest Statement}

The authors have no conflict of interest to declare.

\section{Open Science Statement}

Materials, data, and $\mathrm{R}$ analysis code, can be found on the associated Open Science Framework page: osf.io/e8yp2/. The authors wish to thank and acknowledge those who have contributed to the following R packages used in the current analyses: apaTables (Stanley \& Spence, 2018), car (Fox and Weisberg, 2019), cowplot (Wilke, 2019), dplyr (Wickham, François, Henry \& Müller, 2018), effsize (Torchiano, 2020), ggplot2 (Wickham, 2016), plyr (Wickham, 2011), and userfriendlyscience (Peters, 2018), and to Allen et al. (2019) for example code to create Figure 1.

\section{Contributions}

The following statements summarise the contributions of the authors according to the CRediT taxonomy. GM takes responsibility for Conceptualization, Investigation, Project Administration and Writing (original draft). TRE takes responsibility for the Software, Supervision, Validation and Visualisation. Both authors share responsibility for Data Curation, Formal Analysis, Methodology, Resources and Writing (review \& editing). 


\section{References}

Aalto, A., Heponiemi, T., Keskimaki, I., Kuusio, H., Hietapakka, L., Lamsa, R., Sinervo, T. and Elovainio, M. (2014) "Employment, Psychosocial Work Environment And Well-Being Among Migrant And Native Physicians In Finnish Health Care". The European Journal Of Public Health 24 (3), 445-451

Abe, J. (2018) "Personality, Well-Being, And Cognitive-Affective Styles: A CrossSectional Study Of Adult Third Culture Kids". Journal Of Cross-Cultural Psychology 49 (5), 811-830

Albrecht, S. and Andreetta, M. (2011) "The Influence Of Empowering Leadership, Empowerment And Engagement On Affective Commitment And Turnover Intentions In Community Health Service Workers". Leadership In Health Services 24 (3), 228-237

Al-Maskari, F., Shah, S., Al-Sharhan, R., Al-Haj, E., Al-Kaabi, K., Khonji, D., Schneider, J., Nagelkerke, N. and Bernsen, R. (2011) "Prevalence Of Depression And Suicidal Behaviors Among Male Migrant Workers In United Arab Emirates". Journal Of Immigrant And Minority Health 13 (6), 1027-1032

Allen, M., Poggiali, D., Whitaker, K., Marshall, T. R., and Kievit, R. A. (2019). "Raincloud Plots: A Multi-platform Tool for Robust Data Visualization". Wellcome Open Research, 4

Andresen, M., Goldmann, P. and Volodina, A. (2017) "Do Overwhelmed Expatriates Intend To Leave? The Effects Of Sensory Processing Sensitivity, Stress, And Social Capital On Expatriates' Turnover Intention". European Management Review 15 (3), 315-328

Ang, S., Van Dyne, L. and Koh, C. (2006) "Personality Correlates Of The Four-Factor Model Of Cultural Intelligence". Group \& Organization Management 31 (1), 100-123

Arnett, J. (2000) "Emerging Adulthood: A Theory of Development From The Late Teens Through The Twenties.". American Psychologist 55 (5), 469-480

Aycan, Z. (1997) "Expatriate Adjustment As A Multifaceted Phenomenon: Individual And Organizational Level Predictors". The International Journal of Human Resource Management 8 (4), 434-456

Barringer, C. (2000) "Counseling Third Culture Kids." in Annual Conference Of The American Counseling Association. held 2000

Beaverstock, J. (2011) "Servicing British Expatriate 'Talent' In Singapore: Exploring Ordinary Transnationalism and The Role Of The 'Expatriate' Club". Journal of Ethnic And Migration Studies 37 (5), 709-728

Bhuian, S. and Al-Jabri, I. (1996) "Expatriate Turnover Tendencies In Saudi Arabia: An Empirical Examination". The International Journal of Organizational Analysis 4 (4), 393407

Black, ]. S. (1988). "Work role transitions: A study of American expatriate managers in Japan”. Joumal of Intemational Business Studies, 19: 277-294. 
Black, J. and Stephens, G. (1989) "The Influence of The Spouse On American Expatriate Adjustment And Intent To Stay In Pacific Rim Overseas Assignments". Journal of Management 15 (4), 529-544

Black, J., Mendenhall, M. and Oddou, G. (1991) "Toward A Comprehensive Model Of International Adjustment: An Integration Of Multiple Theoretical Perspectives". Academy of Management Review 16 (2), 291-317

Bonebright, D. (2010) "Adult Third Culture Kids: HRD Challenges and Opportunities". Human Resource Development International 13 (3), 351-359

BPS (2014) [online] available from <https://www.bps.org.uk/sites/bps.org.uk/files/Policy/Policy\%20$\% 20$ Files/BPS\%20Code\%20of\%20Human\%20Research\%20Ethics.pdf > [7 October 2019]

BPS (2017) Ethics Guidelines for Internet-Mediated Research (2017) | BPS [online] available from <https://www.bps.org.uk/news-and-policy/ethics-guidelines-internetmediated-research-2017> [7 October 2019]

BPS (2018) Code of Ethics and Conduct (2018) | BPS [online] available from <https://www.bps.org.uk/news-and-policy/bps-code-ethics-and-conduct> [7 October 2019]

Brace, N., Kemp, R. and Snelgar, R. (2009) SPSS For Psychologists. Basingstoke: Palgrave Macmillan

Brookfield Global Relocation Services (2016) Breakthrough To The Future Of Global Talent Mobility - 2016 Global Mobility Trends Survey [online] available from <http://globalmobilitytrends.bgrs.com> [17 December 2019]

Business Insider (2019) 27 Cities Around the World Where Expats Are Happy, Rents Are Affordable, And Jobs Are Plentiful [online] available from $<$ https://www.businessinsider.com/best-places-to-live-world-cities-expats-living-abroad2017-11?IR=T> [1 October 2019]

Byttner, M. (2012) Career Choices and The Influence Of Third Culture Kids On International Relations. Undergraduate. University of Arkansas, Fayetteville

Caligiuri, P. (1997) "Assessing Expatriate Success: Beyond Just 'Being There'". New Approaches to Employee Management 4, 117-40

Caligiuri, P. and Tarique, I. (2012) "Dynamic Cross-Cultural Competencies and Global Leadership Effectiveness". Journal of World Business 47 (4), 612-622

Cohen, G., Blake, R. and Goodman, D. (2016) "Does Turnover Intention Matter? Evaluating the Usefulness of Turnover Intention Rate As A Predictor Of Actual Turnover Rate". Review of Public Personnel Administration 36 (3), 240-263

Colarelli, S. and Bishop, R. (1990) "Career Commitment". Group \& Organization Studies 15 (2), 158-176

Collings, D., Scullion, H. and Morley, M. (2007) "Changing Patterns of Global Staffing In The Multinational Enterprise: Challenges To The Conventional Expatriate Assignment And Emerging Alternatives". Journal Of World Business 42 (2), 198-213 
Cottrell, A. (2002) "Educational And Occupational Choices Of American Adult Third Culture Kids.." in Military Brats And Other Global Nomads: Growing Up In Organizational Families. ed. by Ender, M. Westport, CT: Praeger Publishers

de Eccher, U. and Duarte, H. (2016) "How Images About Emerging Economies Influence The Willingness To Accept Expatriate Assignments". The International Journal Of Human Resource Management 29 (4), 637-663

Demerouti, E., Bakker, A., Nachreiner, F. and Schaufeli, W. (2001) "The Job DemandsResources Model Of Burnout.". Journal Of Applied Psychology 86 (3), $499-512$

Doki, S., Sasahara, S. and Matsuzaki, I. (2018) "Stress Of Working Abroad: A Systematic Review". International Archives Of Occupational And Environmental Health 91 (7), 767-784

Ethics Guidelines For Internet-Mediated Research (2017)| BPS (2019) available from $<$ https://www.bps.org.uk/news-and-policy/ethics-guidelines-internet-mediated-research2017> [26 February 2019]

Eugenia Sánchez Vidal, M., Valle, R. and Isabel Barba Aragón, M. (2007) "Antecedents Of Repatriates' Job Satisfaction And Its Influence On Turnover Intentions: Evidence From Spanish Repatriated Managers". Journal Of Business Research 60 (12), 12721281

EY (2014) Strategic Global Mobility: Unlocking The Value Of Cross-Border Assignments [online] Harvard Business School Publishing. available from $<$ https://www.ey.com/Publication/vwLUAssets/ey-global-mobility-cross-borderassignments-value/\$FILE/ey-HBR-Report.pdf> [4 February 2019]

Faul, F., Erdfelder, E., Buchner, A. and Lang, A. (2009) "Statistical Power Analyses Using G*Power 3.1: Tests For Correlation And Regression Analyses". Behavior Research Methods 41 (4), 1149-1160

Field, A. (2009) Discovering Statistics Using IBM SPSS Statistics. London: SAGE Publications

Finaccord (2014) Global Expatriates: Size, Segmentation And Forecast For The Worldwide Market [online] available from $<$ http://finaccord.com/documents/rp_2013/report_prospectus_global_expatriates_size_segme ntation_forecasts_worldwide_market.pdf> [21 April 2017]

Finaccord (2018) Global Expatriates: Size, Segmentation And Forecast For The Worldwide Market [online] available from <https://www.finaccord.com/press-release_2018global-expatriates-size,-segmentation-and-forecast-for-the-worldwide-market.htm> $\quad[10$ February 2019]

Foldes, H. (2017) "Gender Differences In Work Performance And Adjustment: Do Women Expatriates Measure Up?." in Managing Expatriates: Success Factors In Private And Public Domains. Columbia University Press

Foldes, H., Ones, D. and Sinangil, H. (2017) "Gender Differences In Work Performance And Adjustment: Do Women Expatriates Measure Up?." in Managing Expatriates: Success 
Factors In Private And Public Domains. ed. by Wiernik, B., Rüger, H. and Ones, D. Columbia University Press

Font, A., Moncada, S. and Benavides, F. (2011) "The Relationship Between Immigration And Mental Health: What Is The Role Of Workplace Psychosocial Factors". International Archives Of Occupational And Environmental Health 85 (7), 801-806

Fox, J. and Weisberg, S. (2019). An $\{\mathrm{R}\}$ Companion to Applied Regression, Third
$\begin{array}{llll}\text { Edition. } & \text { Oaks } & \text { Thousand }\end{array}$ https://socialsciences.mcmaster.ca/jfox/Books/Companion/

General Data Protection Regulation (GDPR) (2016) available from <https://gdprinfo.eu/> [4 March 2019]

Gordon, G. and Teagarden, M. (1995) "Corporate Selection Strategies And Expatriate Manager Success." in Expatriate Management: New Ideas For International Business. ed. by Selmer, J. Westport: Quorum, 17-36

Guttormsen, D. (2018) "Does The 'Non-Traditional Expatriate' Exist? A Critical Exploration Of New Expatriation Categories". Scandinavian Journal Of Management 34 (3), 233-244

Guttormsen, D., Francesco, A. and Chapman, M. (2018) "Revisiting The Expatriate Failure Concept: A Qualitative Study Of Scandinavian Expatriates In Hong Kong". Scandinavian Journal Of Management 34 (2), 117-128

Harvey, M. and Buckley, M. (1997) "Managing Inpatriates: Building A Global Core Competency". Journal Of World Business 32 (1), 35-52

Harzing, A. (1995) "The Persistent Myth Of High Expatriate Failure Rates". The International Journal Of Human Resource Management 6 (2), 457-474

Harzing, A. and Christensen, C. (2004) "Expatriate Failure: Time To Abandon The Concept?". Career Development International 9 (7), 616-626

Haslberger, A. (2010) "Gender Differences In Expatriate Adjustment". European Journal Of International Management 4 (1/2), 163

Hippler, T., Brewster, C. and Haslberger, A. (2015) "The Elephant In The Room: The Role Of Time In Expatriate Adjustment". The International Journal Of Human Resource Management 26 (15), 1920-1935

Hom, P., Lee, T., Shaw, J. and Hausknecht, J. (2017) "One Hundred Years Of Employee Turnover Theory And Research.". Journal Of Applied Psychology 102 (3), 530-545

Horak, S. and Yang, I. (2016) "Affective Networks, Informal Ties, And The Limits Of Expatriate Effectiveness". International Business Review 25 (5), 1030-1042

Känsälä, M., Mäkelä, L. and Suutari, V. (2014) "Career Coordination Strategies Among Dual Career Expatriate Couples". The International Journal Of Human Resource Management 26 (17), 2187-2210 
Kivimäki, M., Vanhala, A., Pentti, J., Länsisalmi, H., Virtanen, M., Elovainio, M. and Vahtera, J. (2007) "Team Climate, Intention To Leave And Turnover Among Hospital Employees: Prospective Cohort Study". BMC Health Services Research 7 (1)

Kumarika Perera, H., Yin Teng Chew, E. and Nielsen, I. (2016) "A Psychological Contract Perspective Of Expatriate Failure". Human Resource Management 56 (3), 479-499

Lakens, D., Scheel, A. and Isager, P. (2018) "Equivalence Testing For Psychological Research: A Tutorial". Advances In Methods And Practices In Psychological Science 1 (2), 259-269

Lauring, J., Guttormsen, D. and McNulty, Y. (2019) "Adult Third Culture Kids: Adjustment And Personal Development". Cross Cultural \& Strategic Management 26 (3), $387-400$

Lauring, J., Selmer, J. and Jacobsen, J. (2014) "Business Or Pleasure? Blurring Relocation Categories And Motivation Patterns Among Expatriates". Scandinavian Journal Of Hospitality And Tourism 14 (2), 170-186

Lazarova, M. and Caligiuri, P. (2001) "Retaining Repatriates: The Role Of Organizational Support Practices". Journal Of World Business 36 (4), 389-401

Lazarova, M. and Cerdin, J. (2007) "Revisiting Repatriation Concerns: Organizational Support Versus Career And Contextual Influences". Journal Of International Business Studies 38 (3), 404-429

Lee, J., Weber, M. and Rivera, D. (2018) "A Sociocultural Perspective On Expatriation Willingness: The Mediating Role Of Cultural Intelligence". Journal Of Hospitality Marketing \& Management 28 (1), 124-145

Lee, L. and Sukoco, B. (2010) "The Effects Of Cultural Intelligence On Expatriate Performance: The Moderating Effects Of International Experience". The International Journal Of Human Resource Management 21 (7), 963-981

Lyttle, A., Barker, G. and Cornwell, T. (2011) "Adept Through Adaptation: Third Culture Individuals' Interpersonal Sensitivity". International Journal Of Intercultural Relations 35 (5), 686-694

Maertz, C. and Campion, M. (1998) "25 Years Of Voluntary Turnover Research: A Review And Critique." in International Review Of Industrial And Organizational Psychology. 13th edn. ed. by Cooper, C. and Roberson, I. New York, NY: Wiley, 49-81

McNulty, Y. (2015) "Till Stress Do Us Part: The Causes And Consequences Of Expatriate Divorce". Journal Of Global Mobility: The Home Of Expatriate Management Research 3 (2), 106-136

Meyer, J. and Allen, N. (1991) "A Three-Component Conceptualization Of Organizational Commitment". Human Resource Management Review 1 (1), 61-89

Nathanson, J. and Marcenko, M. (1995) "Young Adolescents' Adjustment To The Experience Of Relocating Overseas". International Journal Of Intercultural Relations 19 (3), 413-424 
Online Surveys (2019) available from <https://www.onlinesurveys.ac.uk/> [4 March

Ortner, T. and Vijver, F. (2017) Behavior-Based Assessment In Psychology. Deutschland: Hogrefe Publishing

Peters G (2018). userfriendlyscience: Quantitative analysis made accessible. doi:10.17605/osf.io/txequ (URL: https://doi.org/10.17605/osf.io/txequ), R package version 0.7.2, <URL: https://userfriendlyscience.com>.

Pickering, J., Crooks, V., Snyder, J. and Morgan, J. (2018) "What Is Known About The Factors Motivating Short-Term International Retirement Migration? A Scoping Review". Journal Of Population Ageing 12 (3), 379-395

Pollock, D. and Van Reken, R. (2009) Third Culture Kids: Growing Up Among Worlds. Boston, MA: Nicholas Brealey Pub

Pollock, D. and Van Reken, R. (1999) The Third Culture Kid Experience. Yarmouth, Me.: Intercultural Press

Puck, J., Holtbrügge, D. and Raupp, J. (2016) "Expatriate Adjustment: A Review Of Concepts, Drivers, And Consequences". Expatriate Management 297-336

PWC (2005) International Assignments: Global Policy And Practice, Key Trends [online] PWC. available from <https://www.pwc.com/gx/en/hr-managementservices/pdf/ia_perspectives_v2.pdf> [19 September 2019]

PWC (2010) Managing Tomorrow's People: The Future Of Work To 2020 [online] PricewaterhouseCoopers. available from <https://www.pwc.com/gx/en/managing-tomorrowspeople/future-of-work/pdf/mtp-future-of-work.pdf> [23 May 2017]

Ren, H., Shaffer, M., Harrison, D., Fu, C. and Fodchuk, K. (2013) "Reactive Adjustment Or Proactive Embedding? Multistudy, Multiwave Evidence For Dual Pathways To Expatriate Retention". Personnel Psychology 67 (1), 203-239

Richter, P. and Hacker, W. (1998) Belastung Und Beanspruchung: Streß, Ermüdung Und Burnout Im Arbeitsleben. Heidelberg: Germany: Asanger

Salamin, X. and Davoine, E. (2015) "International Adjustment Of Female Vs Male Business Expatriates. A Replication Study In Switzerland". Journal Of Global Mobility: The Home Of Expatriate Management Research 3 (2), 183-212

Schaetti, B. and Ramsay, S. (1999) "The Global Nomad Experience: Living In Liminality". Transition Dynamics 198 (2)

Schütter, H. and Boerner, S. (2012) "Illuminating The Work-Family Interface On International Assignments: An Exploratory Approach". Academy Of Management Proceedings 2012 (1), 14082

Selmer, J. (2002) "Practice Makes Perfect? International Experience And Expatriate Adjustment". Management International Review 42 (1), 71-87

Selmer, J. (2006) "Language Ability And Adjustment: Western Expatriates In China". Thunderbird International Business Review 48 (3), 347-368 
Selmer, J. and Lam, H. (2014) "“Third-Culture Kids”". Personnel Review 33 (4), 430445

Selmer, J. and Lauring, J. (2014) "Self-Initiated Expatriates". Cross Cultural Management: An International Journal 21 (4), 422-436

Selmer, J. and Lauring, J. (2012) "Reasons To Expatriate And Work Outcomes Of SelfInitiated Expatriates". Personnel Review 41 (5), 665-684

Selmer, J. and Leung, A. (2003) "International Adjustment Of Female Vs Male Business Expatriates". International Journal Of Human Resource Management 14 (7), 1117 1131

Shaffer, M., Harrison, D. and Gilley, K. (1999) "Dimensions, Determinants, And Differences In The Expatriate Adjustment Process". Journal Of International Business Studies 30 (3), 557-581

Shin, S., Morgeson, F. and Campion, M. (2006) "What You Do Depends On Where You Are: Understanding How Domestic And Expatriate Work Requirements Depend Upon The Cultural Context". Journal Of International Business Studies 38 (1), 64-83

Smith, P. (2004) "Acquiescent Response Bias As An Aspect Of Cultural Communication Style". Journal Of Cross-Cultural Psychology 35 (1), 50-61

Sousa-Poza, A. and Henneberger, F. (2004) "Analyzing Job Mobility With Job Turnover Intentions: An International Comparative Study". Journal Of Economic Issues 38 (1), 113-137

Spence, C., Sturdy, A. and Carter, C. (2018) "Professionals With Borders: The Relationship Between Mobility And Transnationalism In Global Firms". Geoforum 91, 235244

Stanley, D. J., and Spence, J. R (2018) "Reproducible Tables in Psychology Using the apaTables Package". Advances in Methods and Practices in Psychological Science 1 (3), 415431

Sterle, M., Fontaine, J., De Mol, J. and Verhofstadt, L. (2018) "Expatriate Family Adjustment: An Overview Of Empirical Evidence On Challenges And Resources". Frontiers In Psychology 9

Torchiano M (2020). _effsize: Efficient Effect Size Computation_. doi: 10.5281/zenodo.1480624 (URL:https://doi.org/10.5281/zenodo.1480624), R package version 0.8.1, <URL: https://CRAN.R-project.org/package=effsize>.

UN (2017) International Migration Report [online] available from $<$ http://www.un.org/en/development/desa/population/migration/publications/migrationreport/ docs/MigrationReport2015_Highlights.pdf> [21 April 2017]

Urbistat (2019) Demographic Statisticsregion Of BASEL-STADT, Population Density, Population, Average Age, Families, Foreigners [online] available from $<$ https://ugeo.urbistat.com/AdminStat/en/ch/demografia/dati-sintesi/basel-stadt/12/2> [1 October 2019] 
van Bakel, M. (2018) "It Takes Two To Tango: A Review Of The Empirical Research On Expatriate-Local Interactions". The International Journal Of Human Resource Management 30 (21), 2993-3025

van Bochove, M. and Engbersen, G. (2013) "Beyond Cosmopolitanism And Expat Bubbles: Challenging Dominant Representations Of Knowledge Workers And Trailing Spouses". Population, Space And Place 21 (4), 295-309

van der Heijden, J., van Engen, M. and Paauwe, J. (2009) "Expatriate Career Support: Predicting Expatriate Turnover And Performance". The International Journal Of Human Resource Management 20 (4), 831-845

Wade, L. (2016) "Mexico Struggles To Woo Expat Genome Jocks". Science 352 (6285), 507-507

Walters, K. (2006) A Story To Tell: The Identity Development Of Women Growing Up As Third Culture Kids. Masters. Trinity Western University

Wang, M. and Takeuchi, R. (2007) "The Role Of Goal Orientation During Expatriation: A Cross-Sectional And Longitudinal Investigation.". Journal Of Applied Psychology 92 (5), $1437-1445$

Westropp, S., Cathro, V. and Everett, A. (2016) "Adult Third Culture Kids' Suitability As Expatriates". Review Of International Business And Strategy 26 (3), 334-348

Wickham, H. (2011). “The Split-Apply-Combine Strategy for Data Analysis.” Journal of Statistical Software, 40(1), 1-29. http://www.jstatsoft.org/v40/i01/

Wickham, H. (2016). "ggplot2: Elegant Graphics for Data Analysis". Springer-Verlag New York. ISBN 978-3-319-24277-4, https://ggplot2.tidyverse.org.

Wickham, H., François, R., Henry, L. and Müller, K. (2018). “dplyr: A Grammar of Data Manipulation”. R package version 0.7.6. https://CRAN.R-project.org/package=dplyr

Wilke, C. O. (2019) "cowplot: Streamlined Plot Theme and Plot Annotations for 'ggplot2'”. R package version 1.0.0. https://CRAN.R-project.org/package=cowplot

Yeung, S. (2016) "From Cultural Distance To Skills Deficits: "Expatriates," "Migrants" And Swiss Integration Policy". Multilingua 35 (6)

Yunlu, D., Ren, H., Mohler Fodchuk, K. and Shaffer, M. (2018) "Home Away From Home: Community Embeddedness And Expatriate Retention Cognitions". Journal Of Global Mobility: The Home Of Expatriate Management Research 6 (2), 194-208

Zhu, J., Wanberg, C., Harrison, D. and Diehn, E. (2016) "Ups And Downs Of The Expatriate Experience? Understanding Work Adjustment Trajectories And Career Outcomes.". Journal Of Applied Psychology 101 (4), 549-568 